\title{
Identifying and quantifying sources of variability in temporal and spatial soil moisture observations
}

\author{
David J. Wilson, Andrew W. Western, and Rodger B. Grayson \\ Cooperative Research Centre for Catchment Hydrology and Centre for Environmental Applied Hydrology, \\ Department of Civil and Environmental Engineering, University of Melbourne, Parkville, Victoria, Australia
}

Received 6 May 2003; revised 18 September 2003; accepted 28 November 2003; published 20 February 2004.

[1] Soil moisture is an important component of the hydrological cycle. It is a control in the partitioning of energy and water related to evapotranspiration and runoff and thereby influences the hydrological response of an area. Characterizing the temporal and spatial distribution of soil moisture has important hydrologic applications, yet soil moisture varies in response to many processes acting over a variety of scales; the relative importance of different temporal and spatial controls on soil moisture is still poorly understood. In this paper we analyze both temporal and spatial soil moisture data empirically for two catchments in Australia and a further three in New Zealand. Hydrological conditions at these field sites covered a wide range over a 2 year period. The ground-based soil moisture data set is unique in its temporal and, in particular, its spatial coverage. Analyses attempt to isolate and quantify different deterministic sources of variability, measurement error, and a remaining unexplained component of variability. Because of limited data (especially relating to soils) we take a pragmatic approach of removing patterns that we can define in time and space (namely, seasonality and terrain) and then analyzing the unexplained variation. We then look for consistent patterns in this unexplained variability and argue that these are related to meteorological conditions, especially precipitation events, in the temporal case, and a combination of soils and vegetation in the spatial case. We were able to explain most of the observed variance in time and space, and the temporal variance was typically 5 times larger than spatial variance. Seasonality is the dominant source of temporal variability at our sites, although this conclusion obviously depends on climate and does not hold where soil water storage is limited. Most importantly, in controlling the distribution of soil moisture in space, the spatial distribution of soils and vegetation seems to be of similar importance to that of topography, a fact often ignored in hydrological modeling, or else surrogate soils patterns are used, but these are often not well correlated to the actual patterns [Grayson and Blöschl, 2000]. Better methods for defining the spatial properties of soils and vegetation as they affect soil moisture patterns are a key challenge. INDEX TERMS: 1866 Hydrology: Soil moisture; 1875 Hydrology: Unsaturated zone; 1860 Hydrology: Runoff and streamflow; KEYWORDS: Soil moisture, temporal variability, spatial variability, seasonality

Citation: Wilson, D. J., A. W. Western, and R. B. Grayson (2004), Identifying and quantifying sources of variability in temporal and spatial soil moisture observations, Water Resour. Res., 40, W02507, doi:10.1029/2003WR002306.

\section{Introduction}

[2] Soil moisture is an important component of the hydrological cycle. It is a control in the partitioning of energy and water related to evapotranspiration and runoff, and thereby influences the hydrological response of an area. Characterizing the temporal and spatial distribution of soil moisture has important hydrologic applications, yet soil moisture varies both temporally and spatially in response to many processes acting over a variety of scales; the relative importance of different temporal and spatial controls on soil moisture is still poorly understood.

[3] Generally, changes in soil moisture storage are via precipitation $(\mathrm{P})$, evapotranspiration $(\mathrm{ET})$, net lateral flow,

Copyright 2004 by the American Geophysical Union. 0043-1397/04/2003WR002306 or vertical drainage. These changes occur over a wide range of timescales and neither the relative degree of variability in moisture content occurring at different timescales, nor its predictability is clear. To understand the changing dominance of various controls on moisture content in time, the temporal characteristics of precipitation, radiation, humidity and advection (wind) need to be considered. Temporal variation in P occurs at interannual, seasonal and event scales. The seasonal variation in potential evapotranspiration (PET) compared with $\mathrm{P}$ is critical in the temporal variations of soil moisture. It is important to recognize the dominance of radiation variation at the seasonal scale in many climates. However, available energy is only one component controlling PET. Also important are atmospheric saturation deficit, turbulent transport and canopy conductance [Hipps and Kustas, 2000], which all vary at many temporal scales. 
[4] While PET is an important driver, actual ET is generally a fraction of PET and changes in soil moisture, soil characteristics and vegetation characteristics are also important, depending on other temporally varying characteristics such as the degree and density of plant coverage of the surface, soil moisture content, and root distribution [Hillel, 1998, p. 591]. These effects can have a significant effect on temporal variation of ET and thus on soil moisture, especially where annual crops are planted.

[5] Entin et al. [2000] suggest temporal autocorrelation functions of soil moisture may be partitioned into two components: one related to atmospheric forcing, with a timescale of roughly 2 to 3 months; the other related to short term processes such as infiltration, cloud coverage, precipitation, and drainage. Skøien et al. [2003] use the concept of "characteristic scales" in discussing variability over many orders of magnitude. Within this framework they define deterministic scales (e.g., storm size, response time of catchments, seasonality) and stochastic scales (based on correlation analyses in space and time) of hydrological processes. Analyses of the stochastic component of soil moisture data from Australia and New Zealand found that, "in time, soil moisture is close to stationary with characteristic scales on the order of two weeks while in space soil moisture is nonstationary and close to fractal over the extent sampled" [Skøien et al., 2003].

[6] The spatial distribution of soil moisture can be thought of as a pattern that changes through time. This allows us to examine the consequences of various processes on the patterns, or on the change in patterns. At the small catchment and hillslope scale, soil moisture varies spatially due to water routing processes [Dunne and Black, 1970; Beven and Kirkby, 1979; Moore et al., 1988a], differential radiation effects [Moore et al., 1993; Western et al., 1999] and heterogeneity in soil [Hu et al., 1997; Famiglietti et al., 1998; Seyfried, 1998] and vegetation [Qui et al., 2001; Hupet and Vanclooster, 2002] characteristics. That is, landscape affects the distribution of water on and within the surface. These effects are dependent on the general soil moisture status because different processes control the soil moisture under different conditions [Grayson et al., 1997].

[7] From a modeling perspective, it is important to represent spatial organization correctly, with those features most important in determining spatial distribution of soil moisture requiring identification [Grayson et al., 1995; Merz and Plate, 1997; Western et al., 2004]. In seeking to represent and predict the spatial variability of soil moisture, parsimonious models based on terrain indices have been proposed in the literature [e.g., Beven and Kirkby, 1979; Moore et al., 1991; Wilson and Gallant, 2000]. The idea of terrain indices is to represent the key hydrological processes controlling the spatial distribution of soil moisture in a simplified but realistic way [Western et al., 1999]. The ready availability of digital terrain models has lead to terrain indices being one of the most common predictors used to estimate spatial moisture patterns, even in situations where they may not represent the key controlling processes [Grayson and Western, 2001].

[8] The relationship between soil moisture and terrain indices has been studied in a variety of landscapes and has been summarized by Western et al. [1999, 2002]. It is rare for terrain indices to explain more than half the spatial variability in soil moisture, often significantly less. Limitations of terrain indices stem partly from assumptions in their derivation. No static index can be expected to continuously successfully represent all the details of dynamic processes, nor can they capture the changing importance of different spatial controls as moisture conditions change, for example, seasonally.

[9] Terrain indices also assume that terrain is the dominant control on the spatial soil moisture pattern but the importance of soils [Famiglietti et al., 1998; Seyfried, 1998; Houser et al., 1998; Famiglietti et al., 1999], precipitation [Jackson et al., 1993] and vegetation [Hupet and Vanclooster, 2002] in controlling soil moisture content has also been recognized; the spatial distribution of soil moisture may be significantly affected by these factors. Likewise for the impact of the distribution of atmospheric forcing on soil moisture levels [Seyfried, 1998; Houser et al., 2000]. With each of soil, vegetation and meteorology all affecting the spatial distribution of soil moisture to an extent, it is perhaps not surprising that terrain alone has been of limited value in describing soil moisture distributions [Western et al., 1999, 2002, 2004]. Nevertheless, up to $50 \%$ explanation of patterns is hydrologically useful and it has been shown that often the remaining variance is random, or related to another deterministic pattern, such as soil properties.

[10] Given that terrain is often a poor predictor of soil moisture patterns, there must be other factors dominating, for example, soil properties. Where soil properties vary at similar or larger scales than topography, and in a manner not correlated to topography, the effect will be manifested as a patchy or spatially correlated deviation from the topographic signal. Some factors determining the time stability of soil moisture, or the persistence of point soil moisture state over a range of catchment moisture conditions, include soil types, topographic features, vegetation differences, and anthropogenic disturbances.

[11] The relative importance of different controls on soil moisture in both space and time is still poorly understood. In this paper we analyze both temporal and spatial soil moisture data empirically for two catchments in Australia and a further three in New Zealand. Hydrological conditions at these field sites covered a wide range over a two year period. The ground-based soil moisture data set is unique in its temporal and, in particular, its spatial coverage. At each of five field sites, spatial distributions of soil moisture were measured by taking up to 580 point measurements via TDR on spatial grids varying from $40 \mathrm{~m}$ to $10 \mathrm{~m}$ resolution (depending on the field site). Six such spatial distributions were measured for each field site except Tarrawarra, where eight were measured. The analysis attempts to isolate and quantify different deterministic sources of variability, measurement error and a remaining unexplained component of variability. Because of limited data (especially relating to soils), we take a pragmatic approach of removing patterns that we can define in space and time (namely seasonality and terrain) and then analyzing the unexplained variation. We then look for consistent patterns in this unexplained variability and argue that these are related to a combination of soils and vegetation in the spatial case, and meteorological conditions, especially precipitation events, in the temporal 

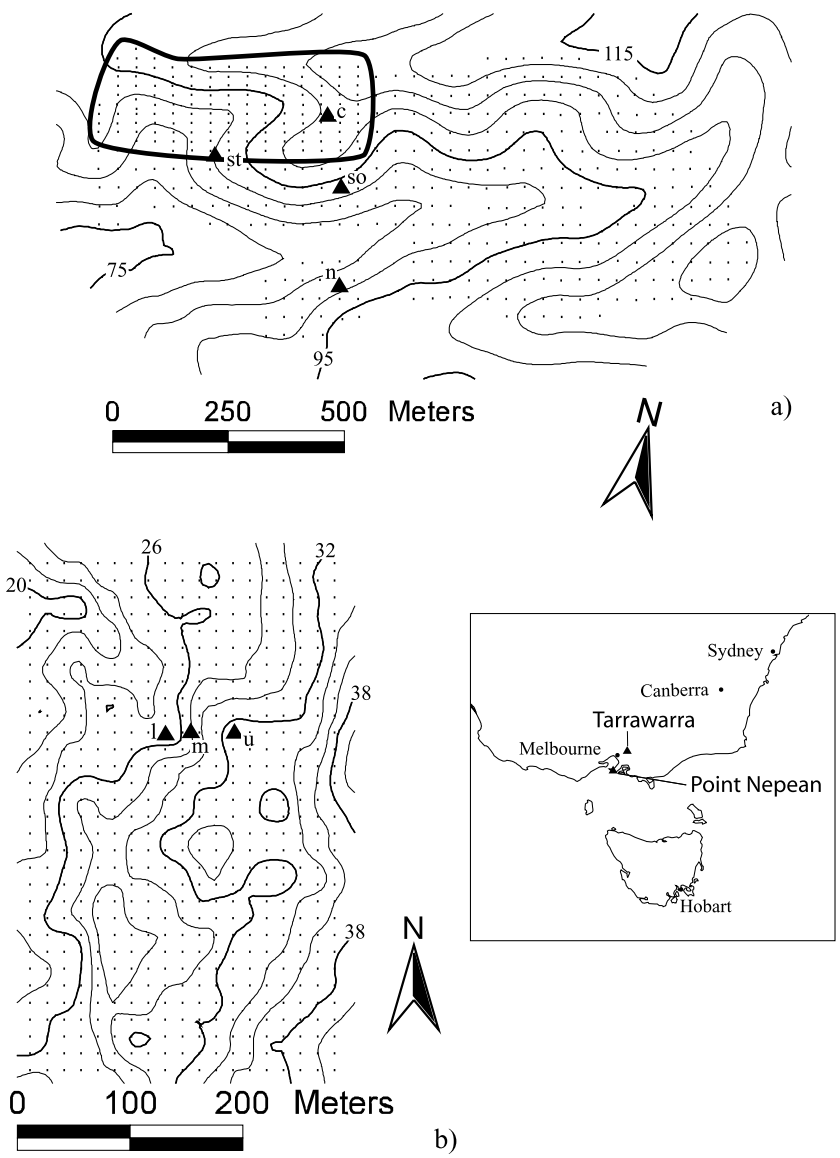

b)

Figure 1. Australian field sites, with soil moisture spatial grid and permanent measuring locations shown; (a) Tarrawarra ("Tarrawarra 1" area circled, "Tarrawarra 2" is the whole site displayed; st, Station; c, Convergent; so, South; n, North) and (b) Point Nepean (u, Upper; m, Mid; 1, Lower).

case. Finally we consider the hydrological implications of our results.

\section{Data and Methods}

[12] The soil moisture data analyzed in this paper consist of spatial and temporal records collected over a two-year period from field sites vegetated with pasture in southeastern Australia and northern New Zealand. The two Australian sites were located close to Melbourne, though on soil of contrasting properties; Tarrawarra on silty clay loam and Point Nepean on sandy soil (Figure 1). Two separate data sets exist for Tarrawarra; one for a small 10.5 ha site (Tarrawarra 1); and another for a larger 55 ha site (Tarrawarra 2) (Figure 1). Annual rainfall and wet environment PET are given in Table 1. Rainfall is quite uniform through the year but PET rates change by almost an order of magnitude between summer and winter, leading to a monthly aridity index (PET/rainfall) varying between 0.2 in June and 2.9 in February. The terrain at both these sites is undulating with mean slopes of $8 \%$ for both sites. There is a difference in the geomorphology of these sites in that Tarrawarra is a fluvial landscape while the Point Nepean site is a dune field that retains its Aeolian morphology.
[13] The New Zealand sites were located in the Mahurangi River catchment and were selected for their representativeness of the wider landscape [Woods et al., 2001]; Satellite Station is an enclosed subcatchment, Clayden's is a divergent hillslope; and Carran's a convergent hillslope (Figure 2). For the Mahurangi River sites, annual rainfall and PET are given in Table 1. Compared with the Australian sites, the seasonality is somewhat weaker in the Mahurangi where the aridity index varies between 0.2 and 1.4 . Soils are clay loams (clay content $30-60 \%$ ) and the terrain is generally undulating to hilly with mean slopes of about $15 \%$. For a detailed record of field investigation and data collection the reader is referred to D. J. Wilson et al. (manuscript in preparation, 2004).

[14] Data utilized here are primarily temporal and spatial measurements of soil moisture in the top $30 \mathrm{~cm}$ of the soil profile, which is representative of the root zone at these sites. Examples of the data sets available are presented in Section 4. Temporally, soil moisture content was recorded by permanently installed CS615 loggers [Campbell Scientific Inc., 1996] every 30 minutes (e.g., Figure 3). At least three such loggers were installed at each field site (Figures 1 and 2); placed along a topographic gradient (four at Tarrawarra 2, six at Satellite Station). Spatially, moisture content was recorded by a mobile TDR-measurement system [Tyndale-Biscoe et al., 1998] at all sites (e.g., Figure 4) on spatial grids varying between 10 and $40 \mathrm{~m}$ spacings, depending on the typical hillslope lengths and site areas at the various sites. Spatial sampling was carried out at least six times over a two year period (eight at Tarrawarra 2), capturing a range of conditions. Sampling of one field site took in the order of either one or two days.

[15] The temporal and spatial data were analyzed separately, but analogously. The general philosophy was to divide the total variance $\left(\sigma_{\text {total }}^{2}\right)$ into components that could be defined empirically by some a priori pattern, then to analyze the consistency of the remaining variance, which was split into unresolved and deterministic components. The unresolved component was further divided into measurement error (based on multiple samples around sites with independent measurements) and a residual unexplained component. For pragmatic reasons of data availability we remove seasonally related variation in time and topographically related variation in space using a priori patterns. That is, temporal variance $\left(\mathrm{v}_{t}\right)$ and spatial variance $\left(\mathrm{v}_{s}\right)$ are comprised of the following components:

$$
\begin{aligned}
\mathrm{v}_{t}= & \text { seasonal }+(\text { spatial }) \text { average residual }+ \text { measurement error } \\
& + \text { unexplained } \\
\mathrm{v}_{s}= & \text { terrain }+(\text { temporal }) \text { average residual }+ \text { measurement error } \\
& + \text { unexplained }
\end{aligned}
$$

The analysis proceeded using the following four steps for each study site separately.

Table 1. Annual Rainfall and PET at Each Field Site

\begin{tabular}{lcc}
\hline \multicolumn{1}{c}{ Field Site } & Annual Rainfall, mm & Annual PET, mm \\
\hline Mahurangi River & 1600 & 1300 \\
Point Nepean & 750 & 830 \\
Tarrawarra & 820 & 830 \\
\hline
\end{tabular}



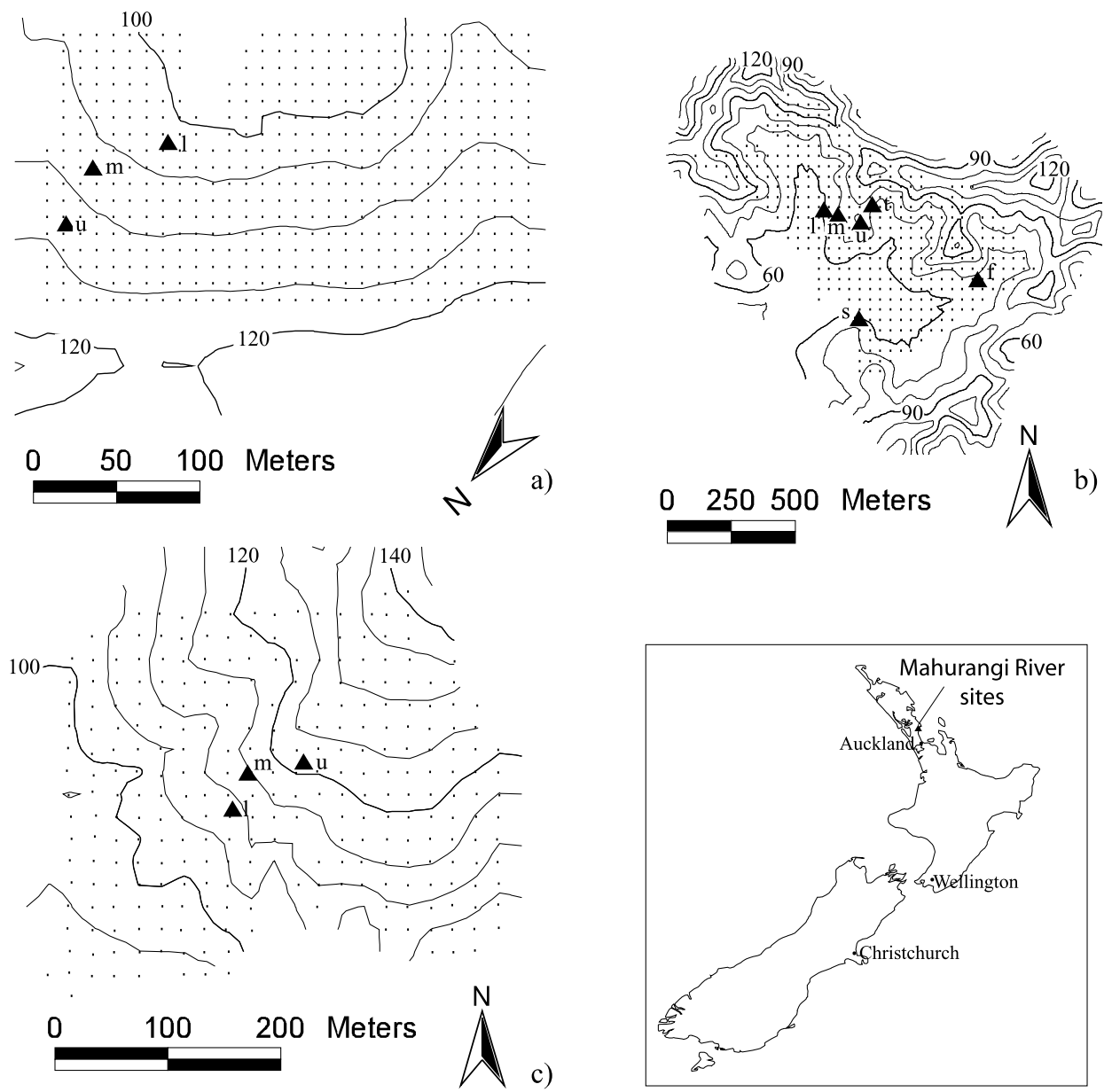

Figure 2. New Zealand field sites, with soil moisture spatial grid and permanent measuring locations shown (u, Upper; m, Mid; 1, Lower). (a) Carran's, (b) Satellite Station (t, Trib; f, Flat; s, Station), and (c) Clayden's.

[16] 1. An a priori empirical pattern was fitted to each (temporal or spatial) soil moisture pattern $\theta_{s}(t)$ or $\theta_{t}(x, y)$ using least squares techniques. The subscripts $s$ and $t$ imply a temporal pattern at location $s$ or a spatial pattern at time $t$, respectively. The explained variance was calculated, $\left(\sigma_{\text {apriori }}^{2}\right)$ and residuals, $r_{s}(t)$ or $r_{t}(x, y)$, were also calculated. The calculation of the a priori patterns is discussed in more detail below.

[17] 2. Consistent variation at a point in time (or in space) was estimated by averaging $r_{s}(t)$ between automatic recorder sites to obtain $\overline{r_{s}(t)}$ (or by averaging $r_{t}(x, y)$ over time to obtain $\overline{\left.r_{t}(x, y)\right)} \cdot \overline{r_{s}(t)}$ was then compared to each of the residual patterns $r_{s}(t)$. To avoid spurious effects, the average residual pattern used as the predictor for station $s^{6}$ was calculated with $r_{s}$ ( $(t)$ excluded, thus several average residual patterns were calculated for each study site. The explained $\left(\sigma_{\text {avresid }}^{2}\right)$ and unexplained variance from this step were calculated for each pattern. The variance explained by $\overline{r_{s}(t)}$ variance, or the deterministic component in time, is thought to be related (in approximate order of importance) to precipitation events, short timescale changes in evaporative forcing and temporal changes in vegetation. An analogous approach was used for the spatial patterns, where the explained variance was interpreted as some deterministic (and time stable) but unknown pattern. In space this pattern is thought to depend mainly on soils properties since the vegetation was spatially quite uniform at each site.

[18] 3. Estimates of the random measurement error were also made and these were used to divide the unexplained variance from step 2 into measurement error $\left(\sigma_{\text {error }}^{2}\right)$ and a residual unexplained component, $\left(\sigma_{\text {unexp }}^{2}\right)$. For the spatial case these estimates were made for each study site based on the variance of repeated multiple measurements of soil moisture made within a small area patches $\left(<1 \mathrm{~m}^{2}\right)$. These measurements were made for a number of patches on each of the sampling occasions and the variance was averaged across all the patches and occasions. While $\sigma_{\text {error }}^{2}$ varied between sites it was typically about $2(\mathrm{~V} / \mathrm{V} \%)^{2}$. For the temporal case the errors were assumed to be $2(\mathrm{~V} / \mathrm{V} \%)^{2}$ on the basis of calibration information.

[19] 4. The a priori patterns fitted to the data in step 1 were derived as follows. The temporal pattern consisted of a two-component (i.e., 12 and 6 month periods) Fourier series fitted to an average annual soil moisture time series $\left(\overline{\theta_{s}(t)}\right)$. The average annual series was calculated by averaging moisture values from all sites within a sample catchment, recorded on a specific day of the year. Because only two years of data were available, there is some uncertainty in this pattern. This will have lead to some overestimation of the importance of the seasonal signal (due to the optimal 


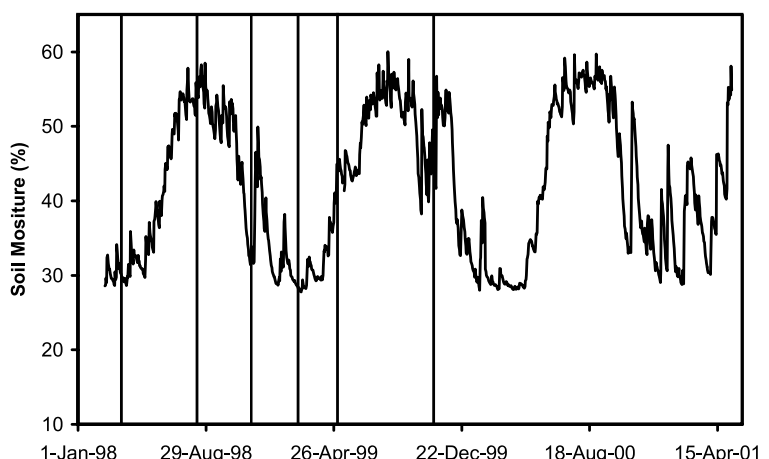

(a)

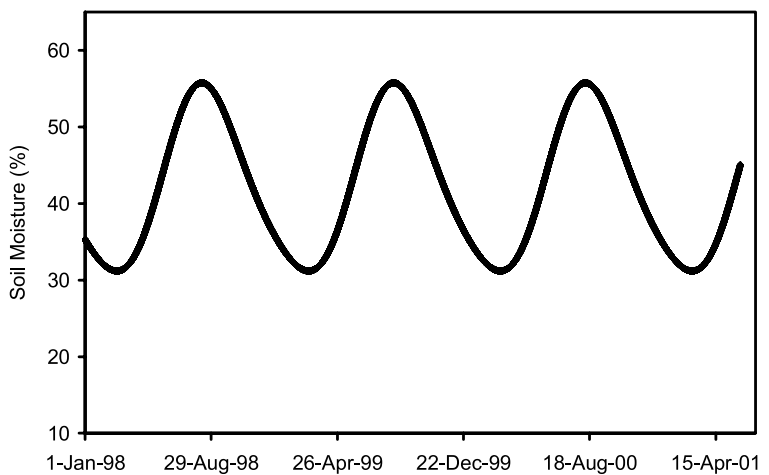

(b)

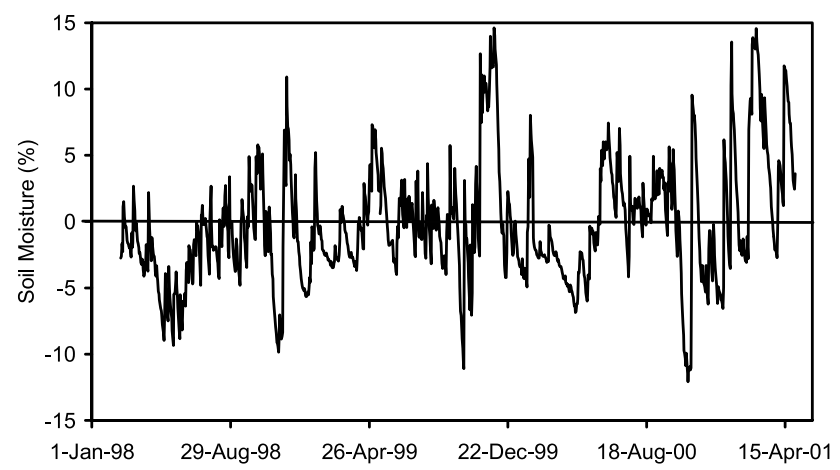

(c)

Figure 3. (a) Temporal record of soil moisture averaged over 0-30 cm; Station location of Satellite Station field site. Six instances of spatial sampling indicated by vertical lines. (b) Seasonal signal of moisture at Station. (c) Mean residual of all sites at satellite station, except station.

fitting), at the expense of larger scale (i.e., interannual) variability and nonstationarity. The average residual series $\left(r_{s}(t)\right)$ was calculated by averaging the residual series $\left(r_{s}(t)\right)$ for each time series record. Spatially, topographic patterns

Figure 4. Spatial distribution (40 $\mathrm{m}$ grid) of soil moisture averaged over $0-30 \mathrm{~cm}$ depth, (a) measured at Satellite Station field site, 22-25 November 1998; 3 m elevation contours, (b) spatial distribution based on terrain indices, and (c) mean residual of all measurement occasions except November 1998. See color version of this figure at back of this issue.

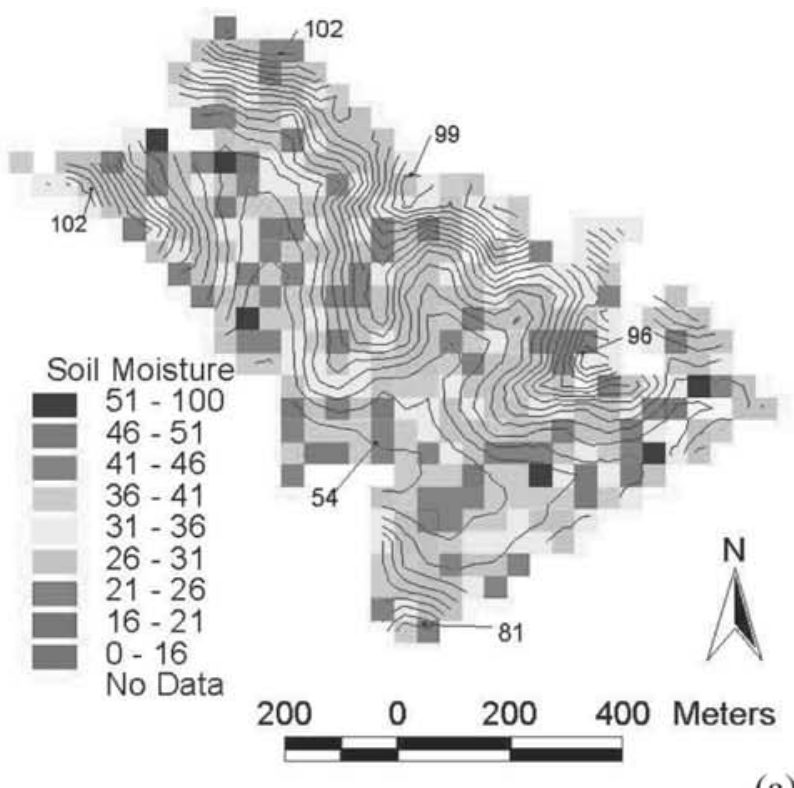

(a)

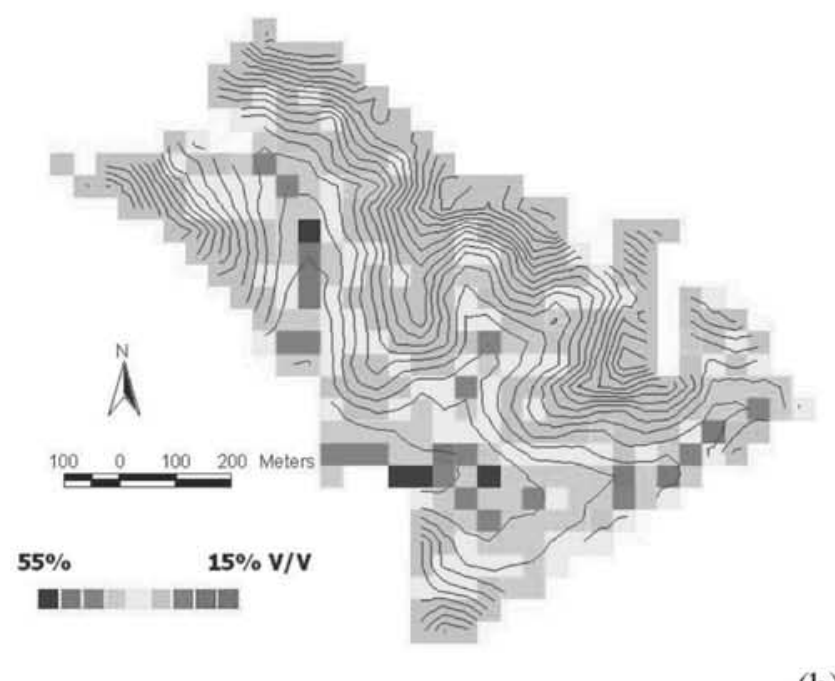

(b)

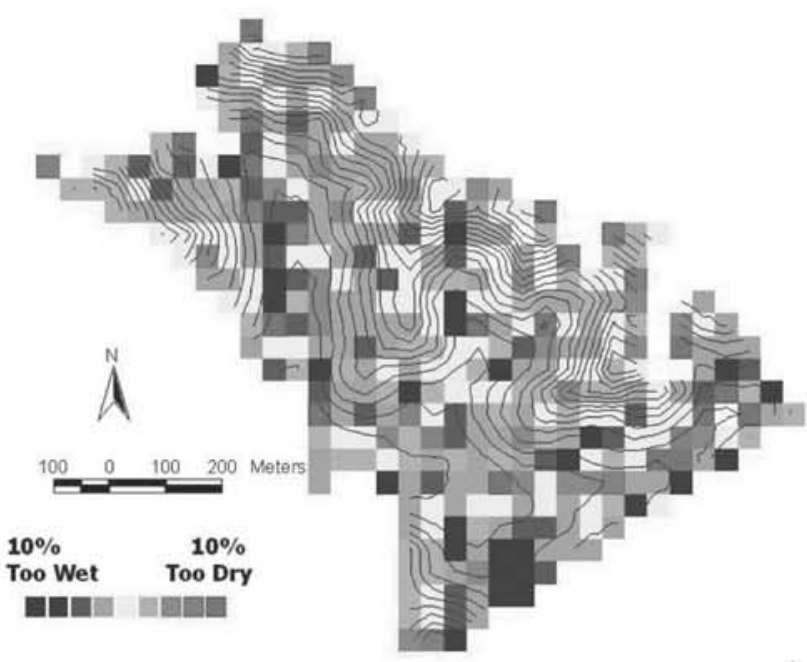

(c) 


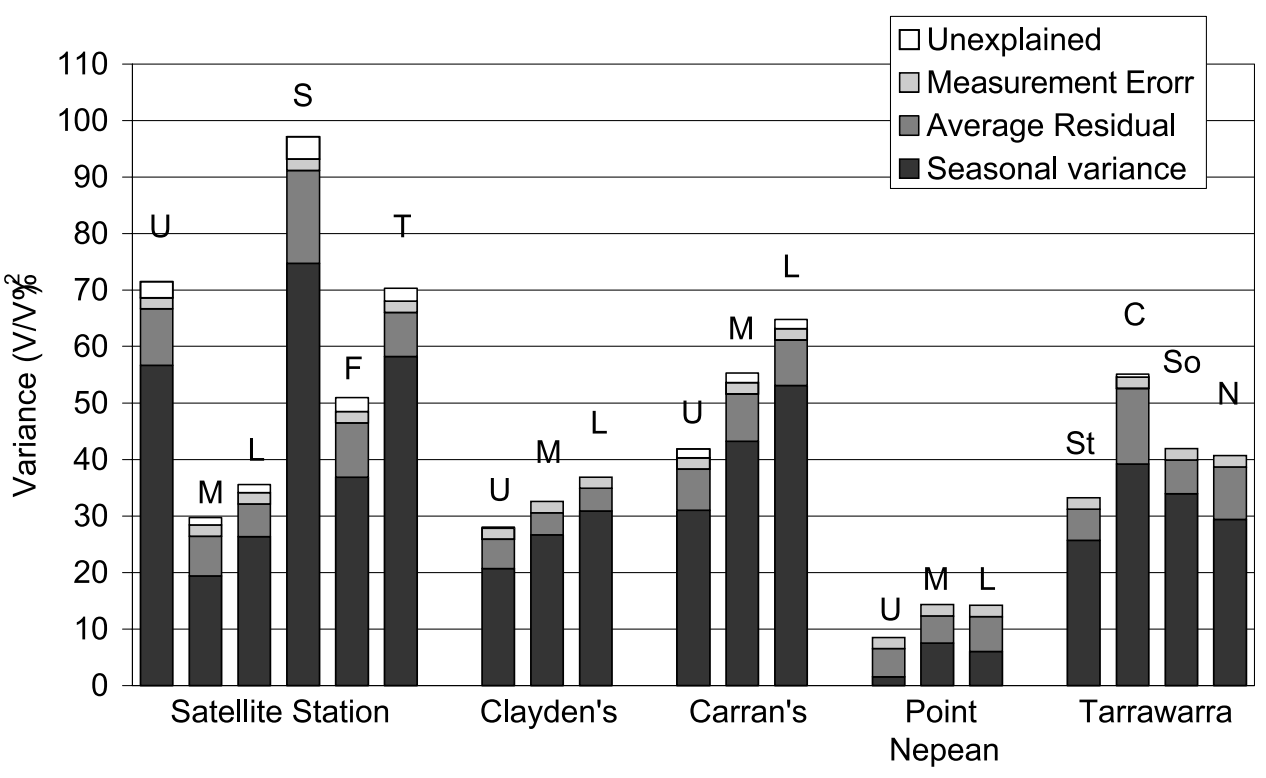

Figure 5. Classified temporal variance in soil moisture at all field sites.

fitted to the soil moisture data included elevation, upslope contributing area, slope, wetness index [Beven and Kirkby, 1979], potential solar radiation index [Moore et al., 1991], lowness and multiresolution valley bottom flatness index [Gallant and Dowling, 2003]. Stepwise multiple linear regression was used to select and fit the predictor patterns $\left(\theta_{t}(x, y)\right)$ to each spatial soil moisture pattern, which were used to calculate residual patterns $\left(r_{t}(x, y)\right)$. The average residual pattern $\left(\overline{r_{t}(x, y)}\right)$ was calculated averaging the residual patterns for each field site.

\section{Results}

\subsection{Temporal Behavior}

[20] Measurements of soil moisture through time $\left(\theta_{S}(t)\right)$ indicate changes in soil moisture content occurring at different scales; a seasonal and an event scale (Figure 3). Nineteen such temporal soil moisture series were available. In each case, the series was separated into seasonal and event-scale components. For example, observations from a point at Satellite Station known as "Station" were found to have seasonal characteristics depicted in Figure 3a. The temporal pattern is identical on an annual basis and can be thought of as the deterministic component of the signal over a long timescale, or the a priori component (e.g., Figure $3 b$ ). Residual series $\left(r_{s}(t)\right)$ were found by removing the seasonal signal from each set of observations. Within each field site, residual series for each point location were averaged to create a fitted average residual signal $\left(\overline{r_{s}(t)}\right)$ (e.g., Figure $3 \mathrm{c}$ ). Fluctuation in the series of fitted average residuals occurs at timescales corresponding to individual storm events. Combining the fitted deterministic signal with the fitted average residual signal gives the best estimate of a soil moisture series. Differences between this best estimate and observations are due to both random measurement error and other unexplained variance.

[21] The total variance $\left(\sigma_{\text {total }}^{2}\right)$ at each monitoring station is shown as the total column height in Figure 5. The greatest temporal variance in moisture content was observed at three of the six Satellite Station logging points; Station, Upper and Trib. Upper was on a ridgeline, while Station and Trib were placed midway along a slope. Apparently, no topographic reasons explain the difference in $\sigma_{\text {total }}^{2}$ observed among the Satellite Station points; logging point Mid was topographically similar to Station and Trib, yet $\sigma_{\text {total }}^{2}$ at Mid was less than half that of either Station or Trib (Figure 5). Topographic position seems not to control soil moisture temporal $\sigma_{\text {total }}^{2}$ at Satellite Station. At Clayden's and Carran's, however, a trend between $\sigma_{\text {total }}^{2}$ and topographic position is evident, with sites lower in the landscape displaying larger $\sigma_{\text {total }}^{2}$ (Figure 5). A similar trend is apparent at Point Nepean. At Tarrawarra, the three logging locations on mid-slopes, Station, South and North, have similar temporal $\sigma_{\text {total }}^{2}$. The convergent location, however, has a higher temporal $\sigma_{\text {total }}^{2}$ (Figure 5).

[22] Statistical characteristics of the temporal $\sigma_{\text {total }}^{2}$ were divided between the seasonal and event scales. Over all field sites, between 18 and $84 \%$ of the temporal $\sigma_{\text {total }}^{2}$ of the observed moisture content series is explained by the variance in the seasonal signal $\left(\sigma_{\text {apriori }}^{2}\right)$ (Figure 5). Of the New Zealand sites, the smallest component of variance explained by $\sigma_{\text {apriori }}^{2}$ was $65 \%$ (Satellite Station Mid). On average, $77 \%$ of temporal $\sigma_{\text {total }}^{2}$ was explained by $\sigma_{\text {apriori }}^{2}$ at the New Zealand sites.

[23] Similarly, between $71 \%$ (Convergent) and $81 \%$ (South) of temporal $\sigma_{\text {total }}^{2}$ is explained by $\sigma_{\text {apriori }}^{2}$ at Tarrawarra, Australia. In contrast, on the sandy soils of Point Nepean, $\sigma_{\text {apriori }}^{2}$ explains only between $18 \%$ (Upper) and $53 \%$ (Mid) of temporal $\sigma_{\text {total }}^{2}$ (Figure 5). $\sigma_{\text {avresid }}^{2}$ is more important to $\sigma_{\text {total }}^{2}$ on the sandy soil. Temporal variance was explained at all sites (except Point Nepean) to a lesser extent by the series of averaged residuals. At Point Nepean, $\mathrm{r}_{s}(t)$ accounts for between 33\% (Mid) and 59\% (Upper) of the temporal $\sigma_{\text {total }}^{2}$, while for all the other sites the highest was 24\% (Tarrawarra Convergent).

[24] Very little of temporal $\sigma_{\text {total }}^{2}$ remained unexplained after the combinations of variance in the seasonal series $\left(\sigma_{\text {apriori }}^{2}\right)$, variance in the average residual series $\left(\sigma_{\text {avresid }}^{2}\right)$ 


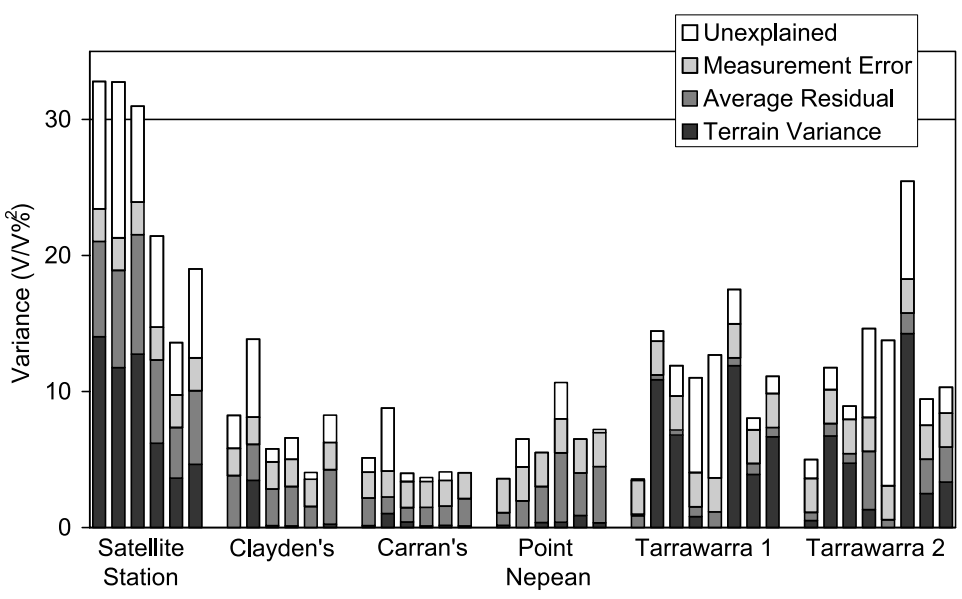

Figure 6. Classified spatial variance in soil moisture at all field sites.

and that of measurement error $\left(\sigma_{\text {error }}^{2}\right)$ were accounted for. Overall, the proportions of $\sigma_{\text {total }}^{2}$ are roughly consistent between CS615 locations at all sites except Point Nepean. Here $\sigma_{\text {apriori }}^{2}$ (seasonal signal) was relatively small, while $\sigma_{\text {avresid }}^{2}$ (attributable to event-scale series), $\sigma_{\text {error }}^{2}$ (measurement error) and $\sigma_{\text {unexp }}^{2}$ (unexplained causes) was consistent between CS615 locations but quite different to the other sites. Soil texture, the relative presence of organic matter and soil structure are all recognized to affect the moisture storage capacity of a soil [Hillel, 1998, p. 466]. Soil texture, for example, influences moisture holding capacity, as fine textured soils retain water more effectively than sandy soils. For Point Nepean, where water is not retained in the profile over long time periods, the seasonal pattern of moisture content is not important relative to the event-scale pattern.

\subsection{Spatial Behavior}

[25] Measurements of the spatial distribution of soil moisture indicate that processes operating at a variety of scales control the distribution (Figure 4). Soil moisture distribution can be partly explained by terrain, and partly by other spatially varying attributes.

[26] $\sigma_{\text {total }}^{2}$ at each monitoring location is shown as the total column height in Figure 6 . The greatest spatial $\sigma_{\text {total }}^{2}$ was observed for different occasions at Satellite Station and Tarrawarra. These two locations comprised subcatchments, as opposed to the other locations, which are hillslope segments. At Satellite Station, $\sigma_{\text {total }}^{2}$ depended on overall moisture condition of the field site, with greater spatial $\sigma_{\text {total }}^{2}$ observed in drier conditions than wet. At all other locations, $\sigma_{\text {total }}^{2}$ fluctuated and showed no clear trend with moisture condition (Figure 6).

[27] Terrain controls on soil moisture have been shown to exist in numerous studies, with the best-performed terrain indices typically including the wetness index [Beven and Kirkby, 1979], where convergent gullies are modeled as wet and divergent hillslopes dry. Combining a number of indices in an MLR process allowed the terrain signal to be isolated from the observed distribution. This was done for each spatial measurement (e.g., Figure 4b). Terrainbased maps are a linear combination of the following terrain indices: elevation, upslope contributing area, slope, wetness index, potential solar radiation index, lowness, multiresolution valley bottom flatness index. The optimum combina- tion of weighted indices was calculated by a Multiple Linear Regression of all indices against observed soil moisture for a given occasion. Figure $4 \mathrm{~b}$ shows the terrain-based distribution for Satellite Station in November 1998. This is the best distribution that terrain can explain. Correlations between terrain-based distribution and the observed distribution appear in Table 2.

[28] For each measurement occasion, the observed spatial distribution differs from the terrain-based distribution by a particular amount. For each measurement occasion the distribution of residuals was calculated. Residual maps were calculated for every measurement occasion $\left(\mathrm{r}_{t}(x, y)\right)$ and averaged to provide a distribution of average residual effects $\left(\overline{r_{t}(x, y)}\right)$ (e.g., Figure 4c).

[29] Statistical characteristics of the Terrain and NonTerrain -scale distributions were then found and compared. Over all field sites, up to $57 \%$ of the spatial $\sigma_{\text {total }}^{2}$ of the observed moisture content series is explained by $\sigma_{\text {apriori }}^{2}$ (the terrain component) (Figure 6). Of the New Zealand sites, the smallest component of $\sigma_{\text {total }}^{2}$ explained by $\sigma_{\text {apriori }}^{2}$ was 0\% (Clayden's February 1999 and November 1999). On average, $36 \%$ of spatial $\sigma_{\text {total }}^{2}$ was explained by $\sigma_{\text {apriori }}^{2}$ at the catchment sites, Satellite Station and Tarrawarra.

[30] On the divergent and convergent hillslope sites of New Zealand, Clayden's and Carran's respectively, just 5\% of the spatial $\sigma_{\text {total }}^{2}$ is explained by $\sigma_{\text {apriori }}^{2}$ on average. On the sandy soils of Point Nepean, $\sigma_{\text {apriori }}^{2}$ also explains only $5 \%$ of the spatial $\sigma_{\text {total }}^{2}$ on average, with a high of 13 and a low of $0 \%$ (Figure 6 ). $\sigma_{\text {avresid }}^{2}$ is far more important to $\sigma_{\text {total }}^{2}$ on the sandy soil. This is likely due to the low waterholding capacity and deep freely draining nature of these sandy soils and the corresponding lack of opportunity for lateral redistribution to occur.

[31] Local terrain can therefore sometimes explain a useful proportion of the spatial distribution of soil moisture at the sites analyzed. This is quite consistent with other results from the literature [e.g., Zavlasky and Sinai, 1981; Burt and Butcher, 1985; Moore et al., 1988b; Ladson and Moore, 1992; Jordan, 1994; Moore and Thompson, 1996; Nyberg, 1996; Grayson et al., 1997; Grayson and Western, 1998; Famiglietti et al., 1998; Western et al., 1999; Western and Grayson, 2000; Green et al., 2001].

[32] At Satellite Station spatial $\sigma_{\text {total }}^{2}$ diminishes with increasing average moisture condition. The relative impor- 
Table 2. Correlation R Between Soil Moisture and a Range of Terrain Attributes Selected by MLR ${ }^{\mathrm{a}}$

\begin{tabular}{|c|c|c|c|c|c|c|c|c|c|}
\hline \multicolumn{2}{|c|}{ Satellite Station } & \multicolumn{2}{|c|}{ Clayden's } & \multicolumn{2}{|c|}{ Carran's } & \multicolumn{2}{|c|}{ Point Nepean } & \multicolumn{2}{|c|}{ Tarrawarra 2} \\
\hline Date & Value & Date & Value & Date & Value & Date & Value & Date & Value \\
\hline March 1998 & 52.2 & March 1998 & 41.7 & April 1998 & 30.7 & July 1998 & 19.1 & June 1998 & - \\
\hline Aug. 1998 & 42.9 & Aug. 1998 & 15.4 & Aug. 1998 & 14.5 & Nov. 1998 & 22.3 & Oct. 98 & 64.1 \\
\hline Nov. 1998 & 55.6 & Nov. 1998 & 12.1 & Nov. 1998 & 17.6 & Jan. 1999 & - & Oct. 98 & 63.4 \\
\hline Feb. 1999 & 57.0 & Feb. 1999 & - & Feb. 1999 & 15.2 & April 1999 & 18.9 & Jan. 1999 & 29.0 \\
\hline May 1999 & 44.9 & May 1999 & 14.3 & May 1999 & 27.6 & Aug. 1999 & 30.3 & April 1999 & 26.1 \\
\hline Nov. 1999 & 46.6 & Nov. 1999 & - & Nov. 1999 & 15.7 & Oct. 1999 & 16.9 & Juy 1999 & 41.6 \\
\hline & & & & & & & & Aug. 1999 & 45.5 \\
\hline & & & & & & & & Oct. 1999 & 61.2 \\
\hline
\end{tabular}

${ }^{\mathrm{a} C}$ Correlations are in percent.

tance of $\sigma_{\text {apriori }}^{2}, \sigma_{\text {avresid }}^{2}$ and $\sigma_{\text {unexp }}^{2}$ remains approximately constant, however, over a range of moisture conditions. At Clayden's and Carran's, $\sigma_{\text {avresid }}^{2}$ remains relatively constant over a range of moisture conditions, while $\sigma_{\text {apriori }}^{2}$ and $\sigma_{\text {unexp }}^{2}$ vary with no relation to the overall moisture condition.

[33] At Point Nepean, the general trend is for an increase in $\sigma_{\text {total }}^{2}$ with increasing wetness. While this is the opposite trend to that observed for Satellite Station, we should remember that moisture content at Point Nepean was always very low. The change in $\sigma_{\text {total }}^{2}$ at Point Nepean is typically due to changes in $\sigma_{\text {avresid }}^{2}$ and $\sigma_{\text {unexp }}^{2}$ (nonterrain sources). At Point Nepean there are observable variations in soil type, particularly clay content that are important in determining the spatial soil moisture pattern. At Tarrawarra, $\sigma_{\text {total }}^{2}$ and its components, generally increase with increasing wetness.

[34] Most of the changes in spatial $\sigma_{\text {total }}^{2}$ through time are due to changes in $\sigma_{\text {apriori }}^{2}$ (the component attributable to terrain). $\sigma_{\text {avresid }}^{2}$ and $\sigma_{\text {error }}^{2}$ are reasonably constant over the range of moisture conditions, however fluctuations are seen in $\sigma_{\text {apriori }}^{2}$ and $\sigma_{\text {unexp }}^{2}$.

[35] In summary, $\sigma_{\text {total }}^{2}$ in the temporal pattern of moisture content dominates over that in the spatial pattern, with temporal variance up to 10 times greater than spatial variance (Figures 5 and 6). In time the most important contribution to temporal $\sigma_{\text {total }}^{2}$ is the seasonal signal.

\section{Discussion}

[36] This discussion focuses on two issues: (1) reasons for the similarity and differences noted between individual sites and (2) the relative importance of temporal and spatial controls affecting the variance of soil moisture. In part 2 we identify the key site characteristics that determine how much variability we can explain (where this differs substantially between sites).

[37] Temporally, the major source of $\sigma_{\text {total }}^{2}$ is $\sigma_{\text {apriori }}^{2}$ (seasonal signal) (Figure 5). This is particularly true for the New Zealand data, where in excess of $75 \%$ of the temporal $\sigma_{\text {total }}^{2}$ could be attributed to seasonal behavior. $\sigma_{\text {avresid }}^{2}$, however, described only a small proportion of $\sigma_{\text {total }}^{2}$. For the New Zealand sites this can be explained by two factors: (1) relatively frequent rainfall throughout 1998 and 1999 and (2) soils of high water storage capacity. Few major peaks or troughs were observed in the temporal rainfall series, so soil moisture was rarely influenced greatly by short-term events. Rather, the series of average residuals were noisy and bore little relation to series of rainfall. Soils of high clay content and large storage tend to smooth temporal variability at short timescales. In heavier soils with restricted deep drainage there is also the potential for lateral flow, which will affect different sites in different ways and thus reduce the spatial coherence of the temporal variations, as evidenced by the higher variability of the downslope sites at Clayden's, Carran's and Tarrawarra.

[38] For Point Nepean, where soils are sandy, $\sigma_{\text {apriori }}^{2}$ is relatively less important. Here, as expected, $\sigma_{\text {avresid }}^{2}$ explains a greater proportion of the temporal $\sigma_{\text {total }}^{2}$. Rapid spikes in moisture content correspond directly with rainfall events such that the variance of the residual series of the three stations Upper, Mid, and Lower, explain a relatively large part of $\sigma_{\text {total }}^{2}$.

[39] Spatially, either $\sigma_{\text {apriori }}^{2}$ (terrain pattern) or $\sigma_{\text {avresid }}^{2}$ (average residual pattern) are generally the major sources of $\sigma_{\text {total }}^{2}$ (Figure 6). Terrain influence on spatial $\sigma_{\text {total }}^{2}$ is most strongly seen at the two field sites comprising subcatchments; Satellite Station and Tarrawarra; as opposed to hillslope segments due to the wider range of terrain positions at these sites. At all sites, particularly Clayden's, Carran's and Point Nepean, the proportion of spatial $\sigma_{\text {total }}^{2}$ explained by $\sigma_{\text {avresid }}^{2}$ is considerable. The average residual patterns represent the action of spatially persistent processes unrelated to those described by terrain indices.

[40] Both temporally and spatially, a large range exists in both inter-site and intrasite $\sigma_{\text {total }}^{2}$. At Satellite Station the largest temporal $\sigma_{\text {total }}^{2}$ occurs at locations Station, Trib and Upper, while Flat, Mid and Lower vary relatively little (Figure 5). Temporal $\sigma_{\text {total }}^{2}$ (seasonal) is larger at Station, Trib and Upper; these are the points that dry most rapidly. Given that rain fell frequently in New Zealand throughout the two year period, moisture content is limited by drainage and evapotranspiration rather than by rainfall. Points where either the soil drains most effectively, or the where soils have a lower wilting point (e.g., more clay), display the strongest seasonal behavior. The effect of topography is dominated by other controls when considering seasonal influences. Analysis of the spatial correlation structure of soil moisture at Satellite Station indicates that there is an unusually large small-scale component of the spatial variability at this site, compared with the others [Western et al., 2004]. Western et al. [2004] suggested that this small-scale variability might be related to: "lateral flow occurring at depths considerably below $30 \mathrm{~cm}$; variability of soils on the hillslopes; and/or, a soil pipe network that is sufficiently extensive to rapidly drain the entire hillslope". It is probable that a common cause lies behind this small-scale spatial variability and the lack of topographic signal in the temporal variability. 
[41] Likewise at other field sites, temporal $\sigma_{\text {apriori }}^{2}$ accounts for the majority of temporal $\sigma_{\text {total }}^{2}$. Water holding capacity affects the proportion of $\sigma_{\text {total }}^{2}$ described by $\sigma_{\text {apriori }}^{2}$ and $\sigma_{\text {avresid }}^{2}$; logically more capacity for water storage will lead to a stronger seasonal signal for a given forcing with both seasonal and event components, because the small scale variations will be smoothed to a greater extent. Terrain position may affect the degree of temporal $\sigma_{\text {total }}^{2}$ described by $\sigma_{\text {apriori }}^{2}$, but cannot be used in a predictive sense, based on the data analyzed here.

[42] Spatially, mean residual patterns account for systematic differences between and within sites and are a significant component of spatial $\sigma_{\text {total }}^{2}$. Given that the terrain indices used represent a range of terrain-related processes, residual spatial patterns represent spatial controls not related to topography. And given also that vegetation was the same for all sites, the residual maps are probably surrogate distributions for effective soil properties.

[43] Temporally, average residuals explain a small proportion of temporal $\sigma_{\text {total }}^{2}$; in this context residuals are patterns that occur at timescales other than seasonal. Most of the temporal variability in soil moisture around the seasonal signal is brought about by storm events and subsequent ET, vertical drainage and lateral redistribution.

[44] In general the variability in the patterns of average spatial residuals is at quite small scales, certainly smaller than the hillslope scale (Figure 4c). A similar observation was also made by Western et al. [1999] for patterns of soil moisture residuals for individual days. Thus there are some significant sources of spatial variability at small scales. In contrast, temporally most of the variability occurs at quite large scales (is explained by the seasonal pattern). This probably reflects the fundamentally different nature of transformation of spatial and temporal variability in different components of the catchment system found by Skøien et al. [2003]. They found that spatial variability was shifted to smaller and smaller scales as water moved through catchment systems but that temporal variability was shifted to progressively larger scales as water moved through the same systems. They argued that this was due to fundamentally different behavior of hydrologic processes in space and time. In time, storage in the catchment smooths variability; this occurs to a greater extent as water moves through larger stores, for example groundwater systems, which have longer characteristic timescales than soil water stores. In space, catchment heterogeneity acts to add variability at small scales.

[45] Implications for hydrology are the apparent controls on moisture patterns. In time, the control is mainly seasonal on soils with large water holding capacities. This is emphasized when comparing Tarrawarra with Point Nepean. In space, the local control is both terrain and soils (and probably often also vegetation), but even with the sitespecific approach followed here, a significant amount of spatial variance is due to unexplained sources. Perhaps using a single average residual pattern is an incorrect approach for capturing spatial effects other than terrain (most likely soils). This would be the case if patterns of porosity, field capacity and wilting point were different, for example. It could also be an effect of spatial dynamics (which we would also expect to affect the temporal case by creating differences between sites).
[46] Temporally, we can explain much of the fluctuation of soil moisture based on knowledge of local climate, which is generally fairly well known. Since temporal variance dominates, the ability to predict moisture fluctuation a priori with confidence is significant (although we do need to know something about the soil storage). Spatially, the average residual patterns are quite important yet we cannot determine them a priori and we have poor information on the soils and vegetation properties for which they act as surrogates. In space, the terrain component is really the only part for which good data exists, and this rarely accounts for more than half the variance. It is clear from our analysis and from others [e.g., Albertson and Kiely, 2001; Seyfried, 1998] that to make good space-time predictions of soil moisture patterns, we need better information on the effective hydrologic properties of soils and vegetation. This information is difficult to obtain and will require innovative approaches, given the practical limitations of traditional methods of collecting spatial soils data. It is also important to note that commonly available soils maps often do not provide appropriate data to capture the effects on soil moisture patterns [e.g., Houser et al., 2000; Western and Grayson, 2000]. Others have also found spatial heterogeneity to be critical [Blöschl et al., 2001; Skøien et al., 2003] but not well related to commonly available spatial data sets.

[47] Blöschl et al. [2001] focused on spatial patterns of runoff and also found consistent patterns, but like in this paper, these were not related to standard soils or geological information. This makes predicting spatial heterogeneity a challenge for hydrology more generally due to the action of catchments to "roughen" the spatial response (as opposed to smoothing the temporal response).

\section{Conclusions}

[48] In closing it is important to reiterate that we were able to explain most of the observed variance in time and space, and that temporal variance was typically five times larger than spatial variance. Seasonality is the dominant source of variability at our sites, although this conclusion obviously depends on climate and does not hold where soil water storage is limited. Most importantly, in controlling the distribution of soil moisture in space, the spatial distribution of soils and vegetation seems to be of similar importance to that of topography, a fact often ignored in hydrological modeling, or else surrogate soils patterns are used, but these are often not well correlated to the actual patterns [Grayson and Blöschl, 2000]. Better methods for defining the spatial properties of soils and vegetation as they affect soil moisture patterns is a key challenge.

\section{References}

Albertson, J. D., and G. Kiely (2001), On the structure of soil moisture time series in the context of land surface models, J. Hydrol., 243(1-2), $101-119$.

Beven, K. J., and M. J. Kirkby (1979), A physically based, variable contributing area model of basin hydrology, Hydrol. Sci. Bull., 24(1), $43-69$.

Blöschl, G., R. Merz, R. B. Grayson, and A. W. Western (2001), Looking for scale invariant processes: From point to mesoscale, paper presented at Chapman Conference on the State of the Art in Hillslope Hydrology, AGU, Sun River, Oregon, 8-12 Oct.

Burt, T. P., and D. P. Butcher (1985), Topographic controls of soil moisture distributions, J. Soil Sci., 36, 469-486. 
Campbell Scientific Inc. (1996), CS615 Water content reflectometer: Instruction manual, Logan, Utah.

Dunne, T., and R. D. Black (1970), Partial area contributions to storm runoff in a small New England watershed, Water Resour. Res., 6, $1296-1311$

Entin, J. K., A. Robock, K. Y. Vinnikov, S. E. Hollinger, S. X. Liu, and A. Namkhai (2000), Temporal and spatial scales of observed soil moisture variations in the extratropics, J. Geophys. Res., 105(D9), $11,865-11,877$

Famiglietti, J. S., J. W. Rudnicki, and M. Rodell (1998), Variability in surface moisture content along a hillslope transect: Rattlesnake Hill, Texas, J. Hydrol., 210(1-4), 259-281.

Famiglietti, J. S., J. A. Devereaux, C. A. Laymon, T. Tsegaye, P. R. Houser, T. J. Jackson, S. T. Graham, M. Rodell, and P. J. van-Oevelen (1999), Ground-based investigation of soil moisture variability within remote sensing footprints during the Southern Great Plains 1997 (SGP97) hydrology experiment, Water Resour. Res., 35(6), 1839-1851.

Gallant, J. C., and T. I. Dowling (2003), A multiresolution index of valley bottom flatness for mapping depositional areas, Water Resour. Res., 39(12), 1347, doi:10.1029/2002WR001426.

Grayson, R. B., and G. Blöschl (Eds.) (2000), Spatial Patterns in Catchment Hydrology: Observations and Modelling, Cambridge Univ. Press, New York.

Grayson, R. B., and A. W. Western (1998), Towards areal estimation of soil water content from point measurements: Time and space stability of mean response, J. Hydrol., 207(1-2), 68-82.

Grayson, R., and A. Western (2001), Terrain and the distribution of soil moisture, Hydrol. Processes, 15, 2689-2690.

Grayson, R. B., G. Blöschl, and I. D. Moore (1995), Distributed parameter hydrologic modelling using vector elevation data: Thales and TAPES-C, in Computer Models of Watershed Hydrology, edited by V. P. Singh, pp. 669-695, Water Resour. Publ., Highlands Ranch, Colo.

Grayson, R. B., A. W. Western, F. H. S. Chiew, and G. Blöschl (1997), Preferred states in spatial soil moisture patterns: Local and nonlocal controls, Water Resour. Res., 33(12), 2897-2908.

Green, T. R., R. H. Erskine, A. Martinez, M. R. Murphy, L. R. Ahuja, J. D. Salas, and J. A. Ramirez (2001), Spatial crop yield and soil water content: Measurement, scaling and topographic analyses, in MODSIM 2001, pp. 359-364, Modell. and Simul. Soc. of Aust. and N. Z., Canberra.

Hillel, D. (1998), Environmental Soil Physics, Academic, San Diego, Calif.

Hipps, L., and W. Kustas (2000), Patterns and organisation in evaporation, in Spatial Patterns in Hydrological Processes: Observations and Modelling, edited by R. B. Grayson and G. Blöschl, pp. 105-122, Cambridge Univ. Press, New York.

Houser, P. R., W. J. Shuttleworth, J. S. Famiglietti, H. V. Gupta, K. H. Syed, and D. C. Goodrich (1998), Integration of soil moisture remote sensing and hydrologic modeling using data assimilation, Water Resour. Res, 34(12), 3405-3420

Houser, P. R., D. C. Goodrich, and K. H. Syed (2000), Runoff, precipitation and soil moisture at Walnut Gulch, in Spatial Patterns in Catchment Hydrology: Observations and Modelling, edited by R. Grayson and G. Blöschl, pp. 125-157, Cambridge Univ. Press, New York.

Hu, Z., S. Islam, and Y. Cheng (1997), Statistical characterisation of remotely sensed soil moisture images, Remote Sens. Environ., 61, $310-318$.

Hupet, F., and M. Vanclooster (2002), Intraseasonal dynamics of soil moisture variability within a small agricultural maize cropped field, $J$. $H y$ drol., 261(1-4), 86-101.

Jackson, T. J., D. M. Le Vine, A. J. Griffiths, D. C. Goodrich, T. J. Schmugge, C. T. Swift, and P. E. O'Neill (1993), Soil moisture and rainfall estimation over a semiarid environment with the ESTAR microwave radiometer, IEEE Trans. Geosci. Remote Sens., 31(4), 836-841.

Jordan, J. P. (1994), Spatial and temporal variability of stormflow generation processes on a Swiss catchment, J. Hydrol., 152, 357-382.

Ladson, A. R., and I. D. Moore (1992), Soil water prediction on the Konza Prairie by microwave remote sensing and topographic attributes, J. Hydrol., 138, 385-407.
Merz, B., and E. J. Plate (1997), An analysis of the effects of spatial variability of soil and soil moisture on runoff, Water Resour. Res., 33(12), 2909-2922.

Moore, I. D., G. J. Burch, and D. H. MacKenzie (1988a), Topographic effects on the distribution of surface soil water and the location of ephemeral gullies, Trans. ASAE, 31(4), 1098-1107.

Moore, I. D., E. M. O'Loughlin, and G. J. Burch (1988b), A contour-based topographic model for hydrological and ecological applications, Earth Surf. Processes Landforms, 13, 305-320.

Moore, I. D., R. B. Grayson, and A. R. Ladson (1991), Digital terrain modeling: A review of hydrological, geomorphological, and biological applications, Hydrol. Processes, 5, 3-30.

Moore, I. D., T. W. Morton, and J. E. Williams (1993), Modelling environmental heterogeneity in forested landscapes, J. Hydrol., 150, 717-747.

Moore, R. D., and J. C. Thompson (1996), Are water table variations in a shallow forest soil consistent with the TOPMODEL concept?, Water Resour. Res., 32, 663-669.

Nyberg, L. (1996), Spatial variability of soil water content in a covered catchment at Gårdsjön, Sweden, Hydrol. Processes, 10, 89-103.

Qui, Y., B. Fu, J. Wang, and L. Chen (2001), Soil moisture variation in relation to topography and land use in a hillslope catchment of the Loess Plateau, China, J. Hydrol., 240, 243-263.

Seyfried, M. S. (1998), Spatial variability constraints to modeling soil water at different scales, Geoderma, 85(2-3), 231-254.

Skøien, J. O., G. Blöschl, and A. W. Western (2003), Characteristic space scales and timescales in hydrology, Water Resour. Res., 39(10), 1304, doi:10.1029/2002WR001736.

Tyndale-Biscoe, J. P., G. A. Moore, and A. W. Western (1998), A system for collecting spatially variable terrain data, Comput. Electron. Agric., $19,113-128$.

Western, A. W., and R. B. Grayson (2000), Soil moisture and runoff processes at Tarrawarra, in Spatial Patterns in Hydrological Processes: Observations and Modelling, edited by R. Grayson and G. Blöschl, pp. 209-246, Cambridge Univ. Press, New York.

Western, A. W., R. B. Grayson, G. Blöschl, G. R. Willgoose, and T. A. McMahon (1999), Observed spatial organisation of soil moisture and its relation to terrain indices, Water Resour. Res., 35(3), 797-810.

Western, A. W., R. B. Grayson, and G. Blöschl (2002), Scaling of soil moisture: A hydrologic perspective, Annu. Rev. Earth Planet. Sci., 30, $149-180$

Western, A. W., R. B. Grayson, G. Blöschl, and D. J. Wilson (2003), Spatial variability of soil moisture and its implications for scaling, in Scaling Methods in Soil Physics, edited by Y. A. Perchepsky, H. M. Selim, and D. E. Radcliffe, pp. 119-142, CRC Press, Boca Raton, Fla.

Western, A. W., S. Zhou, R. B. Grayson, T. A. McMahon, G. Blöschl, and D. J. Wilson (2004), Spatial correlation of soil moisture in small catchments and its relationship to dominant spatial hydrological processes, J. Hydrol., in press.

Wilson, J. P., and J. C. Gallant (Eds.) (2000), Terrain Analysis: Principles and Applications, John Wiley, Hoboken, N. J.

Woods, R. A., R. B. Grayson, A. W. Western, M. Duncan, D. J. Wilson, R. I. Young, R. Ibbitt, R. Henderson, and T. A. McMahon (2001), Experimental design and initial results from the Mahurangi River Variability Experiment: MARVEX, in Land Surface Hydrology, Meteorology, and Climate: Observations and Modeling, Water Sci. Appl. Ser, vol. 3, edited by V. Lakshmi, J. D. Albertson, and J. Schaake, pp. 201-213, AGU, Washington, D. C

Zavlasky, D., and G. Sinai (1981), Surface hydrology: I- Explanation of phenomena, J. Hydraul. Eng., 107, 1-16.

R. B. Grayson, A. W. Western, and D. J. Wilson, Cooperative Research Centre for Catchment Hydrology and Centre for Environmental Applied Hydrology, Department of Civil and Environmental Engineering, University of Melbourne, Parkville, Victoria 3010, Australia. (d.wilson@ civenv.unimelb.edu.au) 


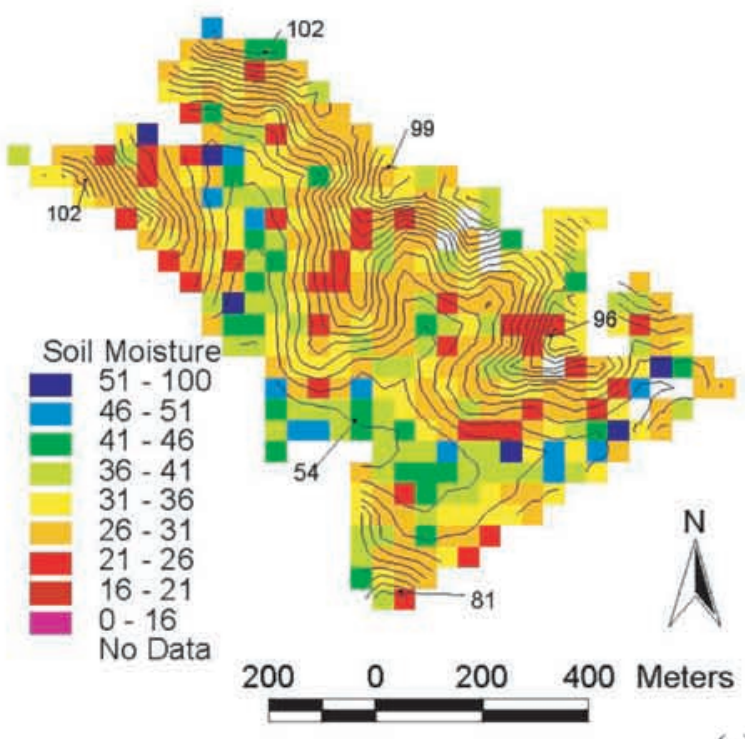

(a)

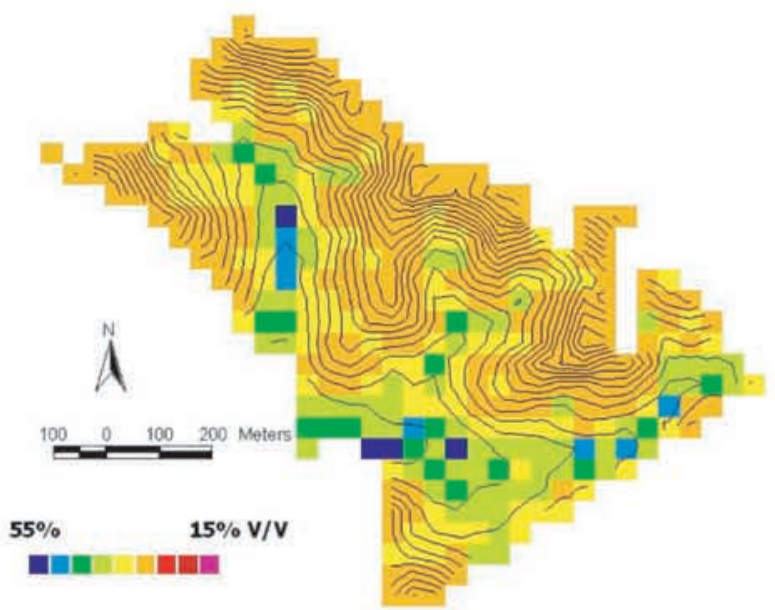

(b)

Figure 4. Spatial distribution (40 $\mathrm{m}$ grid) of soil moisture averaged over $0-30 \mathrm{~cm}$ depth, (a) measured at Satellite Station field site, 22-25 November 1998; 3 m elevation contours, (b) spatial distribution based on terrain indices,

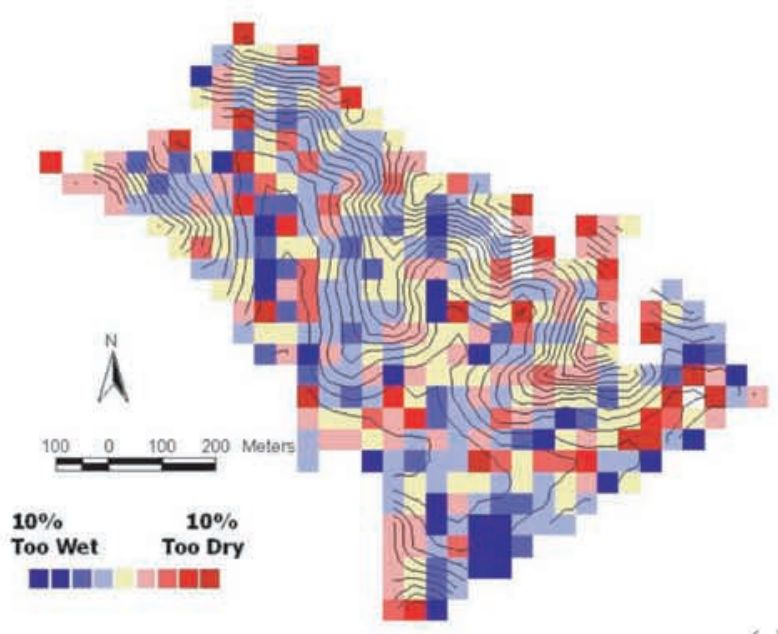
and (c) mean residual of all measurement occasions except November 1998. 